\title{
Modelling of the Deformation of Highly Porous Metals and Alloys under Dynamic Loading
}

\author{
M. N. Krivosheina ${ }^{1, \text { a) }}$, E. V. Tuch ${ }^{1, \text { b) }}$, S. V. Kobenko ${ }^{2, c)}$, M. A. Kozlova ${ }^{1, \text { d) }}$, \\ and I. Yu. Konysheva ${ }^{3, \text { e) }}$ \\ ${ }^{1}$ Institute of Strength Physics and Materials Science SB RAS, Tomsk, 634055, Russia \\ ${ }^{2}$ Nizhnevartovsk State University, Nizhnevartovsk, 628605, Russia \\ ${ }^{3}$ National Research Tomsk Polytechnic University, Tomsk, 634050, Russia \\ a) Corresponding author: marina_nkr@mail.ru \\ b) elenatuch@yandex.ru \\ ${ }^{c)}$ sergeyvk@inbox.ru \\ d) kozlova_ma@mail.ru \\ e) irishkak@@mail.ru
}

\begin{abstract}
The study represents the analysis of numerical simulation of the failure of aluminum targets made of highly porous or solid 2024 alloy under dynamic loading. The calculations employed the finite elements method in threedimensional formulation with the use of proprietary programs. The article presents the results of the numerical simulation of Taylor's test for the projectile made of highly porous aluminum 2024 alloy at the velocities of 75 to $175 \mathrm{~m} / \mathrm{s}$. These results are in a good agreement with the results of the experiments. The peculiarities of the destruction of highly porous aluminum targets are shown.
\end{abstract}

Keywords: highly porous materials, dynamic loading, plastic deformation, Taylor's test, destruction

\section{INTRODUCTION}

Highly porous materials are widely used in the rocket and aerospace engineering, construction, rail and road transport due to their high shock-absorbing, soundproof and strength characteristics. Since such structures made of highly porous materials suffer the severe external exposures, the study of their deformation under dynamic and shock-wave loading is of great interest. The combination of layers of highly porous materials with metal layers can significantly reduce the weight of the protection compared with that of a solid metal target and increase its strength due to the damping properties of highly porous materials [1,2]. This paper demonstrates the differences of deformation and failures in porous and solid materials.

\section{MODEL OF DEFORMATION AND FAILURE OF HIGHLY POROUS MATERIALS}

The numerical simulation of the deformation of porous and solid materials under the dynamic loading was carried out considering the principles of continuum mechanics. The system of the equations describing nonstationary adiabatic movements of compressible isotropic media included the following: continuity equation, motion equation and energy equation [3]. Numerical simulation of the deformation processes of highly porous and solid aluminum alloys was conducted by finite elements method in three-dimensional formulation using the proprietary designed programs [4]. 
The elastic behavior of the isotropic material was described by the generalized Hooke's law, the plastic deformation was determined by the associated flow rule. As a criterion of isotropic material plasticity the Misses criterion was used.

The porosity of the material was modeled using the parameter of porosity introduced by Herrmann [5]. The porosity parameter in the Herrmann's model is stated as the ratio of the specific volume of porous medium $\left(V=V_{\mathrm{m}}+V_{\mathrm{p}}\right)$ to the specific volume of the matrix solid material (initial material)

$$
\alpha_{\mathrm{p}}=\frac{V}{V_{\mathrm{m}}}
$$

The calculation of the density of the porous material $\rho$ and the pressure $P$ accounts the porosity $\alpha_{\mathrm{p}}$ and includes the density $\rho_{\mathrm{m}}$ and the pressure $P_{\mathrm{m}}$ of the solid material:

$$
\rho=\frac{\rho_{\mathrm{m}}}{\alpha_{\mathrm{p}}}, P=\frac{P_{\mathrm{m}}\left(\alpha_{\mathrm{p}} \rho, \varepsilon\right)}{\alpha_{\mathrm{p}}},
$$

where $\varepsilon$ as a specific internal energy.

The porosity parameter $\alpha_{p}$ changes according to the following rule:

$$
\alpha_{\mathrm{p}} P+\alpha_{\mathrm{s}} \ln \left(\frac{\alpha_{\mathrm{p}}}{\alpha_{\mathrm{p}}-1}\right)=0
$$

when

$$
P \leq-\frac{a_{\mathrm{s}}}{\alpha_{\mathrm{p}}} \ln \left(\frac{\alpha_{\mathrm{p}}}{\alpha_{\mathrm{p}}-1}\right)
$$

and where

$$
a_{\mathrm{s}}=\frac{2}{3} \sigma_{\mathrm{s}} \text {. }
$$

The elastic and plastic characteristics of the porous material during the deformation process are determined by the current value of the porosity and by the characteristics of the solid material:

$$
E=E_{\mathrm{m}}\left(1-\frac{\alpha_{\mathrm{p}}-\alpha_{00}}{\alpha_{\mathrm{c}}-\alpha_{00}}\right), G=G_{\mathrm{m}}\left(1-\frac{\alpha_{\mathrm{p}}-\alpha_{00}}{\alpha_{\mathrm{c}}-\alpha_{00}}\right), \sigma_{\mathrm{s}}=\frac{\sigma_{0 \mathrm{~s}}}{\alpha_{\mathrm{p}}},
$$

where $\alpha_{00}$ is the initial porosity of the material, $\alpha_{c}$ is the critical porosity of the destruction of the material in tension, $\alpha_{\mathrm{p}}$ is the current value of porosity, $E_{\mathrm{m}}, G_{\mathrm{m}}, \sigma_{0 \mathrm{~s}}$ are the Young's modulus, shear modulus and tensile strength of the continuous material, respectively.

\section{TAYLOR'S TEST}

This paper considers the numerical simulation of the impact of a highly porous cylinder with a rigid wall. The cylinder material was represented by the highly porous isotropic aluminum 2024 alloy, impact velocities were 75 , 100,150 and $175 \mathrm{~m} / \mathrm{s}$. The initial porosity of the material was 2.12 , which was calculated as the ratio of the density of the solid metal to the average density of the porous metal. The projectile diameter $\mathrm{d}$ was $9.3 \mathrm{~mm}$, the height $L_{0}$ was $23.25 \mathrm{~mm}$. The calculation implemented the elastic and plastic characteristics of the cylinder material that were taken from work [6]. The deformation of the cylinder material was modelled according to the model from [7].

Table 1 contains the results of the numerical simulation of the deformation of highly porous aluminum cylinder and compares them with the experimental data from work [8]. 
TABLE 1

\begin{tabular}{lcccc}
\hline Velocity, $\mathbf{m} / \mathbf{s}$ & 75 & 100 & 150 & 175 \\
\hline Modeling, $\boldsymbol{L} / \boldsymbol{L}_{\mathbf{0}}$ & 0.978 & 0.969 & 0.933 & 0.916 \\
\hline Experiment, $\boldsymbol{L} / \boldsymbol{L}_{\mathbf{0}}[\mathbf{8}]$ & 0.98 & 0.97 & 0.933 & 0.915 \\
\hline Error, $\boldsymbol{\delta}$ & 0.002 & 0.001 & 0 & 0.001 \\
\hline
\end{tabular}

Where $\delta$ is a relative error of the calculations in comparison with experiments and that was estimated as:

$$
\delta=\frac{L_{\text {exp }}-L_{\mathrm{mod}}}{L_{\exp }} .
$$

The results of the numerical simulation of the Taylor's test for the highly porous cylinder are in good agreement with the experimental data. The maximum relative amounted 0.002 (for the cylinder velocity of $75 \mathrm{~m} / \mathrm{s}$ ).

\section{DEFORMATION OF HIGHLY POROUS ALUMINUM TARGETS}

The numerical simulation of the dynamic loading of targets made of highly porous aluminum alloy was carried out with the initial porosity of 2.12. The elastic, plastic and strength characteristics of the target materials were taken from work [6]. The initial velocity of the projectile $\left(V_{0}\right)$ was $300 \mathrm{~m} / \mathrm{s}$, the material of the projectile is steel 3 . The projectile had a cylindrical shape with the diameter $\mathrm{d}$ of $14 \mathrm{~mm}$ and the height $\mathrm{h}$ of $14 \mathrm{~mm}$. The target also had a cylindrical shape with $d=100 \mathrm{~mm}$ and $h=30 \mathrm{~mm}$. In this paper, a normal loading of the target by the projectile was simulated. Free surfaces of the target and the projectile implemented the free boundary conditions. The contact surface between the projectile and the target implemented the sliding condition without friction.

The comparative analysis of the deformation of the target made of highly porous aluminum 2024 alloy was carried out using the failure criterion accounting the accumulated plastic strain:

$$
\psi=\int\left(\mathrm{d} \varepsilon_{j}^{\mathrm{p}} \mathrm{d} \varepsilon_{j}^{\mathrm{p}}\right)^{1 / 2},
$$

where $\varepsilon_{j}^{\mathrm{p}}$ are the components of plastic strain tensor $(j=X, Y, Z)$.

It was supposed that the material fails, when the accumulated plastic strain $\psi$ reaches the value of 0.1 .

More detailed research of the target material deformation requires the consideration of the failure zone in the cross-sections of targets made of solid and porous materials at the moment of $40 \mu \mathrm{s}$ from the beginning of the dynamic loading. Figure 1 shows the failure zone in the cross-section of targets during the compression at the projectile initial velocity of $300 \mathrm{~m} / \mathrm{s}$.

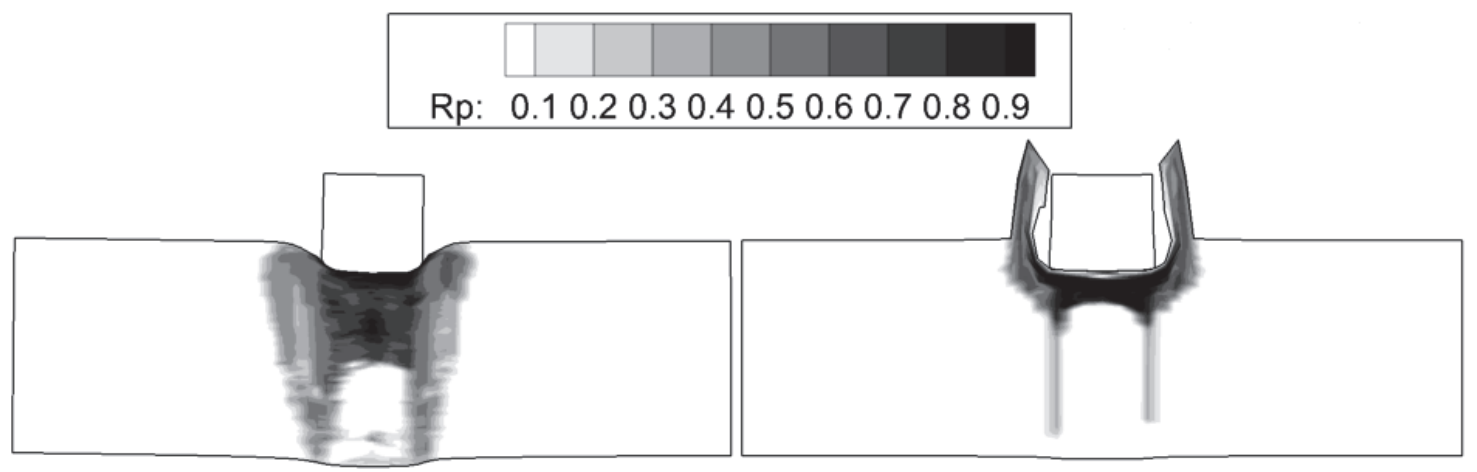

(a)

(b)

FIGURE 1. Failure zone during compression in target material at the moment of $40 \mu \mathrm{s}$ : (a) porous material, (b) solid material 


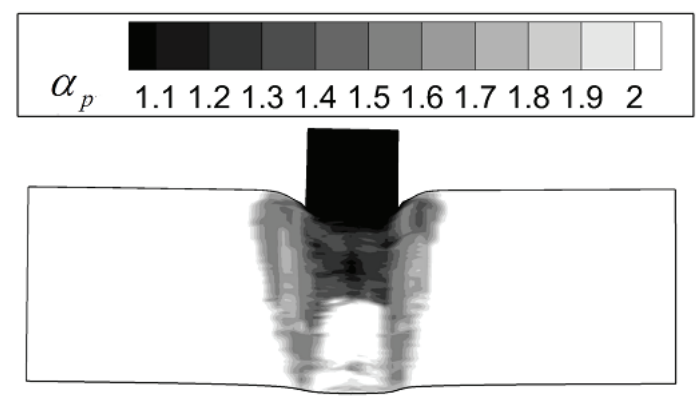

FIGURE 2. Distribution of porosity $\alpha$ in cross-section of target at $40 \mu \mathrm{s}$

Figure 1(a) shows a failure in the porous material at the moment of $40 \mu \mathrm{s}$, the failure being similar to shear plugging. A considerable area of failure was formed under the projectile, however at $37.5 \mu \mathrm{s}$ from the beginning of the dynamic loading the rebounding of the projectile occurred. In the case of the solid target's material, the failure zone was concentrated under the projectile to a significantly lesser extent (Fig. 1(b)) in comparison with the porous material (Fig. 1(a)), the failure being also simulated using the criterion of accumulated plastic deformation. The target also suffered the shear plugging, but the penetration of the projectile was still in process at $40 \mu \mathrm{s}$. The velocity of the projectile center of mass was $32 \mathrm{~m} / \mathrm{s}$. To demonstrate the influence of the target's material porosity on the failure intensity, Figure 2 shows the distribution of porosity in the target's cross section. Immediately under the projectile, the target's porosity approached the value of 1, i.e. the density of the porous material approached to the density of the solid material. This leads to the earlier rebound of the projectile than in the case of the solid material.

Using the same failure criterion for the modeling of porous and solid material failures gives different results for both integral characteristics and the failure in general. Although the volume of the failed porous material is greater than the volume of failed solid material, the penetration of the projectile into the porous material was finished earlier.

\section{SUMMARY}

The presented numerical technique for modeling the processes of deformation of highly porous materials in three-dimensional formulation gives the results that are identical to the experimental data. It was shown that the elastic-plastic deformation and failure of targets made of highly porous and solid material have considerable differences that are determined by the possibility of pore volume reduction for the porous material on compression in the zone of impact loading of the target.

The work was carried out within the framework of the Program of the fundamental scientific researches of the state academies of sciences for 2013-2020.

\section{REFERENCES}

1. G. Lu, B. Wang, and T. Zhang, Int. J. Imp. Engng. 25(10), 981 (2001).

2. B. Wang, T. Zhang, and G. Lu, Int. J. Imp. Engng. 28(5), 499 (2003).

3. L. I. Sedov, Continuum Mechanics (Nauka, Moscow, 1976), Vol. 2.

4. M. N. Krivosheina, E. V. Tuch, and U. A. Khon, Bull. Russ. Acad. Sci. Phys. 76(1), 91 (2012).

5. V. Herrman, Mechanics 5, 96 (1970).

6. Industrial Aluminum Alloys, edited by F. I. Kvasov and I. N. Fridlyander (Metallurgy, 1984).

7. N. N. Belov, N. T. Yugov, D. G. Kopanitsa, and A. A. Yugov, Dynamics of High-Rate Shock and Accompanying Physical Phenomena, Northampton (STT, Tomsk, 2005).

8. G. V. Belov, A. P. Gusarov, V. A. Markov, V. I. Pusev, A. F. Ovchinnikov, V. V. Selivanov, and M. U. Sotskii, Sci. Educ.: Electron. Sci. Tech. Publ. 9, 13 (2012). 